\title{
Reduced late asthmatic response by repeated low-dose allergen exposure
}

\author{
M. Palmqvist, Z-H. Cui, M. Sjöstrand, A. Lindén, J. Lötvall
}

Reduced late asthmatic response by repeated low-dose allergen exposure. $M$. Palmqvist, Z-H. Cui, M. Sjöstrand, A. Lindén, J.Lötvall. C ERS Journals Ltd 2001. ABSTRACT: Allergic asthmatic individuals are often exposed to low-doses of allergen in their everyday life. Extended exposure to allergen has lead to down-regulation of the allergic process in cell systems and in animal models. The aim of this study was to evaluate whether any such inhibitory mechanism of allergic responses can be seen in man in vivo.

Patients with mild asthma were repeatedly and double-blindly exposed to $25 \%$ of the individual dose of allergen that caused an early (EAR) and late asthmatic reaction (LAR). One day after the low-dose allergen or placebo exposure periods, the same individual was given a high-dose allergen challenge. Sputum and blood were collected for the evaluation of eosinophils.

Exposure to repeated low doses of allergen induced increased bronchial methacholine responsiveness $6 \mathrm{~h}$ after the final allergen exposure $(p=0.018)$, and an increase in the number of eosinophils in sputum. By contrast, the late asthmatic response after challenge with a high dose of allergen was significantly attenuated by $\sim 30 \%$ at $24 \mathrm{~h}$ after the final low-dose allergen exposure $(p=0.03)$.

In summary, repeated low doses of allergen given directly to the airways, attenuate the high-dose allergen-induced late response, despite enhanced bronchial hyperresponsiveness to methacholine and elevated sputum eosinophils prior to allergen challenge. Eur Respir J 2001; 17: 872-880.
Lung Pharmacology Group, Dept of Respiratory Medicine and Allergology, Institute of Heart and Lung Diseases, University of Göteborg, Sahlgrenska University Hospital, Göteborg, Sweden.

Correspondence: J. Lötvall, Dept of Respiratory Medicine and Allergology, University of Göteborg, Bruna Stråket 11, 41345 Göteborg, Sweden. Fax: 4631413290

\section{Keywords: Allergen}

asthma

eosinophils

tolerance

Received: January 172000

Accepted after revision January 72001

This work was supported financially by the Vårdal Foundation and the Swedish Heart and Lung Foundation. M. Palmqvist and J. Lötvall were financed by Herman Krefting's Foundation against Asthma-Allergy.
Airborne allergens are present in most homes and in many indoor public areas like schools, day care centres and official buildings [1-4]. It has also been demonstrated that it is difficult to reduce allergen exposure in these environments [5-7]. However, avoidance of allergens may result in decreased bronchial methacholine hyperresponsiveness [8-10]. Thus, allergic individuals are probably continuously exposed to low doses of allergen that may not cause immediate symptoms, but may induce methacholine bronchial hyperresponsiveness [11]. This is also similar to what happens during the pollen season, when bronchial hyperresponsiveness is induced in pollen allergic asthmatics [12-14].

The clinical allergen challenge model utilizing high doses of allergen is well-characterized [15-18]. This type of challenge model often produces both early and late bronchoconstriction in atopic individuals with mild asthma. Recently, efforts have been made to develop models that, in a better way, resemble responses induced during natural allergen exposure [19]. Several studies have now been published based on models giving repeated low doses of inhaled allergen to allergic individuals with mild asthma. These studies show that individualized low doses of allergen have the capacity to induce bronchial hyperresponsiveness [20-24], similar to what can be seen with high doses of allergen [15-17] or during a pollen season [12-14].

Little is known about how repeated low doses of allergen influence the responses to the specific allergen itself. In 1951, it was suggested by HERXHEIMER [25] that a high dose of antigen can cause a severe asthma attack and the patient becomes "hypersensitive" to a second allergen exposure. However, when a smaller dose of allergen was given, the state of "hypersensitivity" could be changed into a "hyposensitive state" [25]. ROSENTHAL et al. [26] have studied the early asthmatic response following repeated allergen exposures, but could not document any change in responsiveness to a subsequent allergen challenge. However, a recent study in the present authors' laboratory, on allergen exposure in the guinea-pig, shows that repeated low doses of allergen strongly attenuate the bronchoconstrictor response to a subsequent high-dose allergen challenge [27]. By contrast, a high-dose allergen exposure does not reduce the response to a later high-dose allergen challenge in this animal model [27].

On the basis of these earlier findings, it was hypothesized that a process of down-regulation of specific allergic airway responses may be induced by repeated low-dose allergen exposure in patients with allergic asthma, which would be in contrast to induced 
methacholine responsiveness [22, 23]. To evaluate whether any such process is present, patients with mild allergic asthma were repeatedly and blindly exposed to $25 \%$ of the dose of allergen shown to cause an early (EAR) and a late asthmatic reaction (LAR) at a screening visit. After the low-dose allergen or placebo exposure periods, the patients were challenged with the same cumulative allergen dose causing an early and late response at the screening visit. To evaluate inflammatory processes in parallel to changes in allergen and methacholine responsiveness, sputum and blood were collected.

\section{Patients and methods}

\section{Patients}

The local Ethics Committee in Gothenburg approved the study. Seven atopic asthmatics, mean age 36 yrs (range 23-47 yrs), with a documented EAR and LAR on a screening bronchial challenge to cat allergen, participated in the study. Skin-prick test (SPT) and radioallergsorbent test (RAST) (CAP-RAST, Pharmacia, Uppsala, Sweden) were all positive to cat (SPT $\geqslant++(\geqslant$ half the size of the positive control) and RAST class $\geqslant 2$ ). Some of the patients were also allergic to pollen, but participated in the study out of the pollen season. None of the patients were sensitized to house dust mite according to SPT, their asthma was mild, and they only used inhaled short-acting $\beta_{2}$-agonists on rare occasions. Mean forced expiratory volume in one second (FEV1) was $89 \%$ predicted (range $65-95 \%$ ). None of the patients were smokers. No other antiasthmatic therapy than inhaled $\beta_{2}$-agonists prn were allowed in the study. Patients with any other significant disease, patients on $\beta$-blocker therapy, or
Table 1.-Patient characteristics

\begin{tabular}{|c|c|c|c|c|c|c|}
\hline Patient & Sex & $\begin{array}{l}\text { Age } \\
\text { yrs }\end{array}$ & $\begin{array}{l}\mathrm{FEV}_{1} \% \\
\text { pred }\end{array}$ & SPT (cat) & $\begin{array}{l}\text { RAST class } \\
\text { (cat) }\end{array}$ & $\begin{array}{c}\text { PD20 } \\
\text { SQ units }\end{array}$ \\
\hline 1 & $\mathrm{~F}$ & 47 & 65 & +++ & 3 & 10 \\
\hline 2 & $\mathrm{~F}$ & 47 & 100 & +++ & 3 & 65 \\
\hline 3 & $\mathrm{~F}$ & 40 & 93 & ++++ & 4 & 225 \\
\hline 4 & $\mathrm{~F}$ & 23 & 85 & +++ & 4 & 1400 \\
\hline 5 & M & 27 & 86 & +++ & 3 & 600 \\
\hline 6 & M & 40 & 114 & +++ & 3 & 80 \\
\hline 7 & $\mathrm{~F}$ & 27 & 82 & +++ & 3 & 50 \\
\hline
\end{tabular}

FEV1: forced expiratory volume in one second; SPT: skinprick test; RAST: radioallergosorbent test; PD20: provocative dose causing a 20\% fall in FEV1; F: female; M: male.

pregnant and breast-feeding female patients, were not included. No patients who owned cats or had regular contact with cats during the study were allowed to participate. Patient characteristics are presented in table 1.

\section{Study design}

The design of the study can be seen in figure 1. After the screening day, patients that could be included in the study were randomized to receive the diluent for allergen (placebo) or an individualized dose of allergen on 7 consecutive days (except Sunday) in a cross-over and double-blind way. An independent laboratory engineer working in a different research group, and not involved in any clinical study procedures or data analysis, performed the blinding procedure.

Screening. In all, 18 patients were called to a screening day, when an interview, an SPT to cat and a bronchial challenge were performed. Seven patients fulfilled the inclusion criteria, where the presence of EAR and LAR

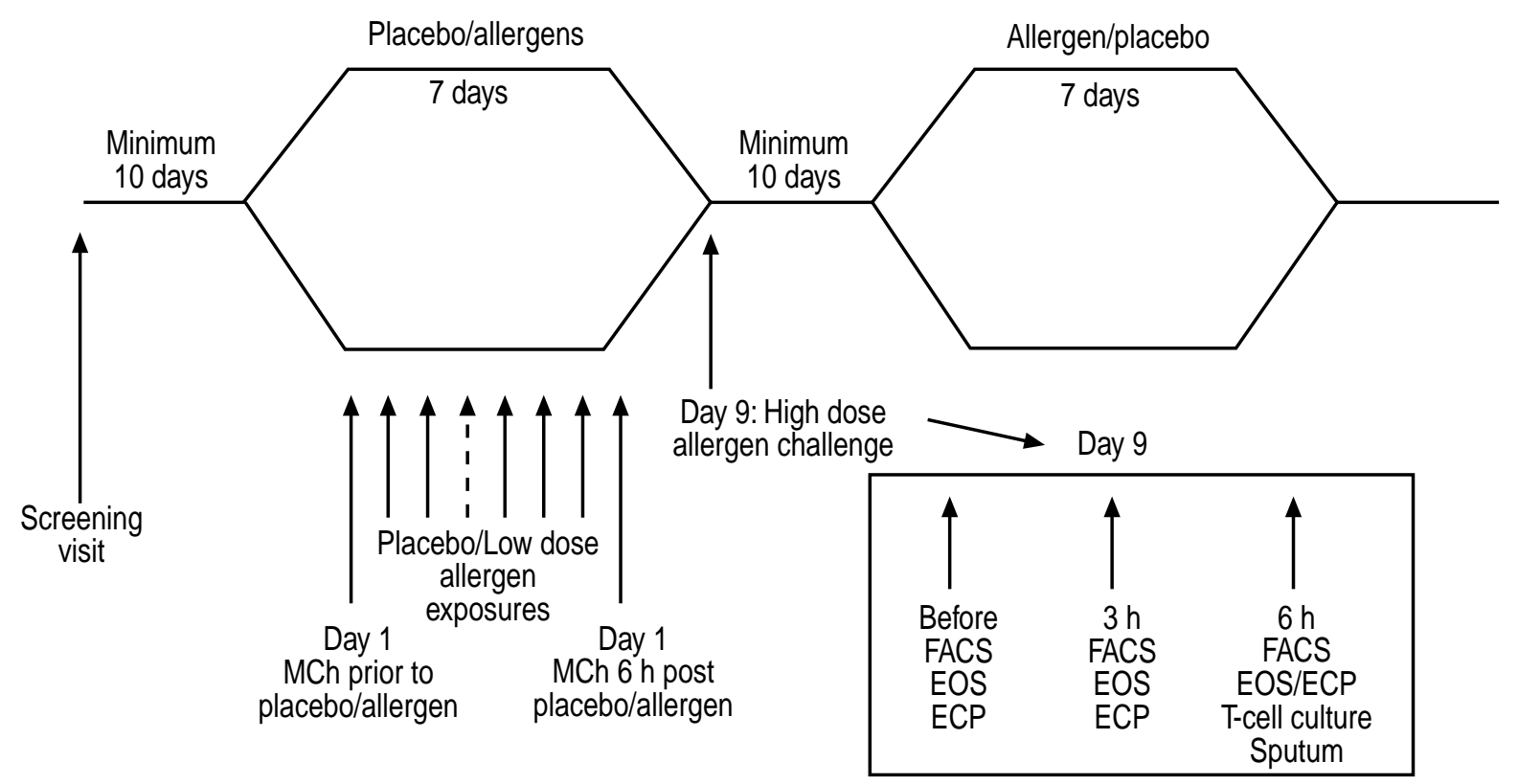

Fig. 1.-Study design. - : low dose individualized allergen exposure or placebo. - - -: Sunday, no exposure. MCh: methacholine; FACS: fluorescence-activated cell sorter; EOS: eosinophils; ECP: eosinophil cationic protein. 
was confirmed. Serum samples were taken prior to screening, and 3 and 6-7 h after the start of allergen challenge. At the end of the screening day, the LAR was interrupted by a dose of $800 \mu \mathrm{g}$ inhaled salbutamol (Diskhaler, GlaxoSmithKline Ltd, Ware, UK) and $30 \mathrm{mg}$ prednisolone given orally. The allergen doses were plotted against the fall in FEV1 on a log-linear curve and the cumulative allergen doses were calculated.

Repeated low-dose allergen exposure. At least 10 days after the screening day, the patients were exposed during 7 consecutive days (day 1-8, not on Sundays) to a lowdose of cat allergen or its diluent, in a randomized, double-blind way. The low-dose cat allergen dose was defined as $25 \%$ of the cumulative provocative allergen dose that caused a fall in FEV1 of $20 \%$ (allergen PD20) on the screening day. On day 1, before the low-dose cat/ diluent exposure, a bronchial methacholine provocation was performed to assess the level of baseline bronchial hyperresponsiveness. After the period of low-dose cat/ diluent exposure on day $8,6 \mathrm{~h}$ after the last low-dose cat/diluent exposure, a second bronchial methacholine provocation was performed. After reversal of the bronchospasm induced by the methacholine provocation, sputum was induced by inhalation of increasing aerosol doses of hypertonic saline solutions (see later).

High-dose bronchial allergen challenge. On day 9, $24 \mathrm{~h}$ after the last low-dose allergen/diluent exposure, the patient was challenged with a single dose of cat allergen, calculated from the cumulative dose of cat allergen that caused a significant reaction on the screening day. FEV1 was followed every hour up to $6 \mathrm{~h}$ after the high-dose allergen challenge. At this time point the allergen response was interrupted by an inhaled dose of $800 \mu \mathrm{g}$ of salbutamol, in order to prepare for induction of sputum during the time for the LAR (see later).

Low-dose bronchial allergen exposures, high-dose allergen challenges, and methacholine provocations

Nebulizer. The administration of allergen and methacholine to the airways by aerosol were all performed with the dosimeter (ME.FAR MB 3, ME.FAR Ellettromedicali, Brescia, Italy). With an inspiratory capacity breath, the patient inhaled the aerosol dose slowly, followed by $5 \mathrm{~s}$ of breath holding. When driven at the used air pressure of $1.65 \mathrm{~kg} \cdot \mathrm{cm}^{-2}$ and an airflow of $70-75 \mathrm{~L} \cdot \mathrm{min}^{-1}$, the particle size of the aerosol is $0.5-5 \mu \mathrm{m}$. The output of aerosol was $10 \mu \mathrm{L}$ per breath, with a nebulization time set to $1 \mathrm{~s}$. Five inhalations on each dose of allergen or methacholine were given. The basal FEV1 (the better of two measurements separated by $1 \mathrm{~min}$ ) must be at least $65 \%$ pred to be allowed to continue with the allergen challenge test.

Screening visit; high-dose bronchial allergen challenge. After measurement of the basal FEV1, the challenge protocol was initiated with inhalation of the diluent of the allergen extract (albumin human $0.3 \mathrm{mg}$, sodium chloride $5 \mathrm{mg}$, sodium hydrogen carbonate $2.5 \mathrm{mg}$, phenol $5 \mathrm{mg}$, aq. ad inject. ad $1 \mathrm{~mL}$ ). After 4 and 5 min, FEV1 was measured, and the best of these was regarded as the baseline value. The allergen challenge (crude cat allergen; Allergological Laboratories, Copenhagen, Denmark, ALK) started with a concentration of 32 standardized quality units $\cdot \mathrm{mL}^{-1}$. FEV1 was measured after 5 and 10 min (the best of two measurements separated by $1 \mathrm{~min}$ ). The lowest FEV1 at 5 or $10 \mathrm{~min}$ was regarded as the reaction to the given dose. If the fall in FEV1 at 10 min was $16-19 \%$, FEV1 was also measured at $15 \mathrm{~min}$, before any additional dose of allergen was given. If the patient reached an FEV1 drop of $20 \%$ at the 15 min measurement, the allergen provocation procedure was stopped. The inhaled allergen was given at doubling concentrations at 10-15-minute intervals, unless a fall in FEV1 of $\geqslant 20 \%$ from baseline value occurred. This reaction was defined as the EAR. No further allergen doses were then administered. FEV1 was measured at 15, 20, 30, 45, $60 \mathrm{~min}$ and every hour up to $7 \mathrm{~h}$ (two measurements of FEV1 at every time point with one min between). The LAR was defined as a fall in FEV1 of $\geqslant 15 \%$ from baseline value on at least one time point between 3 and $7 \mathrm{~h}$ after the allergen dose that caused the EAR. To reverse the LAR, $800 \mu \mathrm{g}$ of inhaled salbutamol and $30 \mathrm{mg}$ of oral prednisolone was given.

Day 1-8, low-dose bronchial allergen exposure. In a randomized and double-blind design, diluent or 1/4 of the allergen PD20 on the screening day, was given repeatedly on 7 days, except on Sundays (day 1-8). FEV1 was measured before the low-dose allergen exposure, and then at 5, 10, 20 and $30 \mathrm{~min}$ after challenge (at every time point, two measurements with 1 min between). The low-dose/diluent periods were separated by $\geqslant 10$ days.

Day 1 and day 8, bronchial methacholine provocation. FEV1 was measured 90 and $180 \mathrm{~s}$ after inhalation of the vehicle (physiological saline), and the best value was used as baseline value. The provocation started with inhalation of methacholine chloride $0.03 \mathrm{mg} \cdot \mathrm{mL}^{-1}$, with measurements of FEV1 after 90 and $180 \mathrm{~s}$. The best value was regarded as the reaction to the given dose. Every fifth min the methacholine concentration was doubled, until a fall in FEV1 of at least $20 \%$ was reached and the methacholine provocation test was stopped. On day 1 the methacholine-induced bronchospasm was allowed to spontaneously resolve for $\sim 30-60 \mathrm{~min}$, before the lowdose allergen/diluent was given. On day $8,800 \mu \mathrm{g}$ of inhaled salbutamol was given to reverse the methacholine-induced bronchoconstriction, and to prepare for the inhalation of hypertonic saline for the induction of sputum.

Day 9, high-dose bronchial allergen challenge. The cumulative dose of cat allergen that was given on the screening day and caused a significant early and late asthmatic reaction, was given as a single dose on day 9 . FEV1 was measured at 5, 10, 15, 20, 30, 45, 60 min and every hour up to $6 \mathrm{~h}$. At $6 \mathrm{~h}, 800 \mu \mathrm{g}$ of inhaled salbutamol was given to prepare for sputum induction, and after sputum induction, $30 \mathrm{mg}$ of oral prednisolone was given to stop the late allergen processes. 


\section{Blood}

Eosinophils and eosinophil cationic protein. On days 1, 4 and 9, blood samples for leukocyte differential count and for serum eosinophil cationic protein S-ECP; CAP, Pharmacia) were collected. On day 9 , at 3 and 6 h after the high-dose allergen challenge, samples were also collected for leukocyte differential count and for S-ECP measurements.

Preparation of blood for fluorescence-activated cell sorter. The samples were stained with combinations of monoclonal antibodies, directly conjugated with fluorochromes. Fluoroscein isothiocyanate-conjugated CD4, phytoerythrin-conjugated CD8 and Per-CPconjugated CD3 (Becton-Dickinson Inc., Mountain View, CA, USA) were used. After washing twice, the cells were analysed on a FACScan flow cytometer, using standardized methods.

Preparation of CD4 and CD8 for cell culture. CD4- and CD8-cells were enriched from samples taken on day 8 , $6 \mathrm{~h}$ after the low-dose allergen exposure, and on day 9, $6 \mathrm{~h}$ after the high-dose allergen challenge (fig. 1). Mononuclear cells were separated using density gradient centrifugation technique (Ficoll-Paque $\mathbb{R}$, Pharmacia), and then washed. CD4 + and CD8 + lymphocytes were enriched using a standardized magnetic separation method (MACS; Miltenyi biotec GmbH, Bergisch Gladbach, Germany). In short, a cocktail of magnetic labelled antibodies against CD11b, CD16, CD19, CD36, CD56 and CD8 or CD4 cells were added to the two fractions of mononuclear cells and the nonmagnetic labelled CD4 + or CD8 + lymphocytes were enriched by depletion, over a magnetic field.

CD4- and CD8-cells were seeded in a 96-well tissue culture plate $\left(4 \times 10^{5}\right.$ cells $^{\cdot}$ well $\left.{ }^{-1}\right)$, together with adherent mononuclear cells. Subsequently, $100 \mu \mathrm{L}$ of culture medium with Concanavallin A (ConA) $\left(10 \mathrm{ng} \cdot \mathrm{mL}^{-1}\right)$ and $\left(6-\mathrm{H}^{3}\right)$ Thymidine $10 \mathrm{mCi} \cdot \mathrm{mL}^{-1}$ (Amersham, Buckinghamshire, UK) was added to determine the proliferation capacity of the cells. After 7 days, cell proliferation was determined by measuring the total amount of incorporated $\left(6-\mathrm{H}^{3}\right)$ Thymidine in a $\beta$-Liquid scintillation counter (Matrix 96, Canberre Packard, Uppsala, Sweden).

\section{Sputum}

Day 8 and 9, sputum induction. Six $\mathrm{h}$ after the last inhalation of low-dose allergen or diluent on day 8 and $6 \mathrm{~h}$ after the high-dose allergen inhalation on day 9, sputum was induced with a method previously described [28]. Briefly, inhaled salbutamol $800 \mu \mathrm{g}$ was given, and increasing concentrations (3,4 and 5\%) of hypertonic saline were given for $7 \mathrm{~min}$ using an ultrasonic nebulizer Omron NE-UO7 (Toranomon, Tokyo, Japan). Sputum was expectorated, placed in a sterile container, and kept cold until processing as described [29]. Sputum plugs were selected, weighed and mixed with 4 volumes sputum weight ${ }^{-1}$ of Sputasol $(6.5 \mathrm{mM}$ dithiothreitol in $100 \mathrm{mM}$ phosphate buffered saline $\mathrm{pH}$ 7.4). The cell suspension was centrifuged for $5 \mathrm{~min}$ at $600 \times g$, and the supernatant was saved at $-70^{\circ} \mathrm{C}$ for further analysis. Cytospins were made with the cell suspension (Cytospin 3, Shandon Inc., UK) and a differential count was made. The sputum supernatant was analysed for interleukin (IL)-5 and eotaxin by commercially available enzyme linked immunosorbent assays from R\&D (R\&D Systems Europe Ltd, Abingdon, UK).

\section{Bone marrow analysis}

CD34+ cells were enriched from the bone marrow crista puncture on day 8 using MACS (Miltenyi biotec $\mathrm{GmbH}$ ), after density gradient centrifugation (FicollPaque B, Pharmacia). A monoclonal magneticallylabelled antibody directed to CD34 was added to the mononuclear cell suspension according to the manufacturer's instructions (MACS). An enrichment procedure with positive selection over a magnetic field, resulted in $\sim 65 \% \mathrm{CD} 34+$ cells, according to fluorescence-activated cell sorter analysis.

The enriched CD34+ cells were cultured in Iscoves medium supplemented with $0.9 \%$ methyl cellulose, $0.5 \mu \mathrm{M} 2-\beta$-mercaptoethanol, $1 \%$ penicillin/streptomycin, $20 \mathrm{mM} \mathrm{L}$-glutamine and $10 \%$ foetal calf serum (all from Sigma, St. Louis, MO). Each culture well (6 well plate; Becton-Dickinson Inc., BD Biosciences Europe, Erembodegem, Belgium) contained $2.5 \mathrm{~mL}$ of this conditioned media, 10,000 cells together with $100 \mathrm{ng} \cdot \mathrm{mL}^{-1}$ recombinant human (rh) stem cell factor (SCF), $10 \mathrm{ng} \cdot \mathrm{mL}^{-1}$ rh Granulocyte-Macrophage colony stimulating factor (GM-CSF) and $10 \mathrm{ng} \cdot \mathrm{mL}^{-1} \mathrm{rh}$ interleukin-5 (IL-5) (all from R\&D Systems Europe Ltd.). Also, 10\% autologous serum from the high-dose allergen challenge time point (during the late response) was added to the cultures. The cells were incubated in $37^{\circ} \mathrm{C}$ in a humidified incubator with $7 \%$ carbon dioxide. Colony forming units (cfus) were counted after 14-16 days.

\section{Statistics}

Seven patients were included in this crossover study. Power calculations show that this number of patients are required to statistically prove, with $80 \%$ power, a $30 \%$ difference of the early and late asthmatic response [30]. For sputum eosinophils, five patients are required to document, with $95 \%$ power, a $50 \%$ difference of the relative number of sputum eosinophils between treatments [31]. The present study shows similar SD for allergen responses as in the previously reported power calculation study [30], as do previous allergen exposure studies in the present authors' department.

The data are presented as mean \pm SEM. Data where baseline values for each period are available, were generally calculated as change from baseline for respective period (treatment period data minus baseline data). The paired t-test was generally used. Data for sputum parameters were analysed using absolute values. For sputum eosinophils, the data were transformed by square root prior to analysis, as has been described previously [32]. For the PD20 methacholine data, a paired nonparametric analysis (Wilcoxon 
signed rank) was used. $\mathrm{p}<0.05$ was adopted as the level of significance for all analyses.

\section{Results}

At the screening allergen day, the patients mean maximal fall in FEV1 was $27.6 \pm 3.7 \%$ up to $1 \mathrm{~h}$ after the high-dose allergen challenge (EAR), and $21.3 \pm 1.7 \% 3-7 \mathrm{~h}$ after challenge (LAR).

\section{Lung function and bronchial responsiveness}

Forced expiratory volume in one second. There was no significant difference in baseline FEV1 on day 1 before the low-dose allergen and diluent exposure period $(2.83 \pm 0.24 \mathrm{~L}$ and $2.93 \pm 0.27 \mathrm{~L}$, respectively, $\mathrm{p}=0.34)$. No significant change in baseline FEV1 was seen during the low-dose allergen exposure period compared to the diluent exposure $(0.20 \pm 0.09 \mathrm{~L}$ and $0.13 \pm 0.11 \mathrm{~L}$, respectively, $\mathrm{p}=0.64)$. The low doses of allergen caused very small immediate changes in FEV1 (fig. 2), which were statistically significant versus respective placebo exposure time point only on day 1 at $10 \mathrm{~min}$ $(\mathrm{p}=0.012)$, on day 2 at $5 \mathrm{~min}(\mathrm{p}=0.01)$ and on day 5 at 5 and $30 \min (\mathrm{p}=0.027$ and $\mathrm{p}=0.032$, respectively).

Methacholine responsiveness. FEV1 before the methacholine provocation procedures on day 1 and day 8 was not significantly different between the low-dose allergen and diluent exposure periods $(3.00 \pm 0.26 \mathrm{~L}$ and $3.09 \pm 0.28 \mathrm{~L}$ before the low-dose allergen/diluent exposure periods respectively, $\mathrm{p}=0.41$, and $2.96 \pm$ $0.26 \mathrm{~L}$ and $3.04 \pm 0.34 \mathrm{~L}$ after the low-dose allergen/ diluent exposure respectively, $\mathrm{p}=0.28$ ). There was no significant difference in baseline PD20 methacholine before the low-dose allergen and the diluent exposure periods $(40.2 \pm 2.2 \mu \mathrm{g}$ and $32.9 \pm 1.9 \mu \mathrm{g}$, respectively $\mathrm{p}=0.40$ ). After the repeated low-dose exposure period the fall in PD20 was $1.29 \pm 0.65$ doubling doses, whereas there was a small improvement during the placebo exposure period, $0.35 \pm 0.15$ doubling doses, $\mathrm{p}=0.018$ between treatment periods (fig. 3 ).

High-dose allergen response. FEV1 before the high-dose allergen challenge on day 9 was not significantly different after the low-dose allergen exposure period compared to after the placebo period, $3.03 \pm 0.29 \mathrm{~L}$ and $3.06 \pm 0.29 \mathrm{~L}, \mathrm{p}=0.65$. After the high-dose allergen challenge on day 9, the response in FEV1 was not significantly different between the two pretreatment periods up to $4 \mathrm{~h}$ after allergen. However, at both 5 and $6 \mathrm{~h}$ after the high-dose allergen challenge (during the time for the initiation of the late asthmatic response), the FEV1 response was significantly attenuated (at $5 \mathrm{~h}-9.7 \pm 4.3 \%$ and $-7.6 \pm 3.6 \%$ after diluent and low-dose allergen, respectively $(\mathrm{p}=0.037)$ and at $6 \mathrm{~h}-14.7 \pm 4.0 \%$ and $-9.7 \pm 3.6 \%$ after diluent and low-dose allergen, respectively $(\mathrm{p}=0.032)$ ) (fig. 4$)$. Thus, the inhibitory
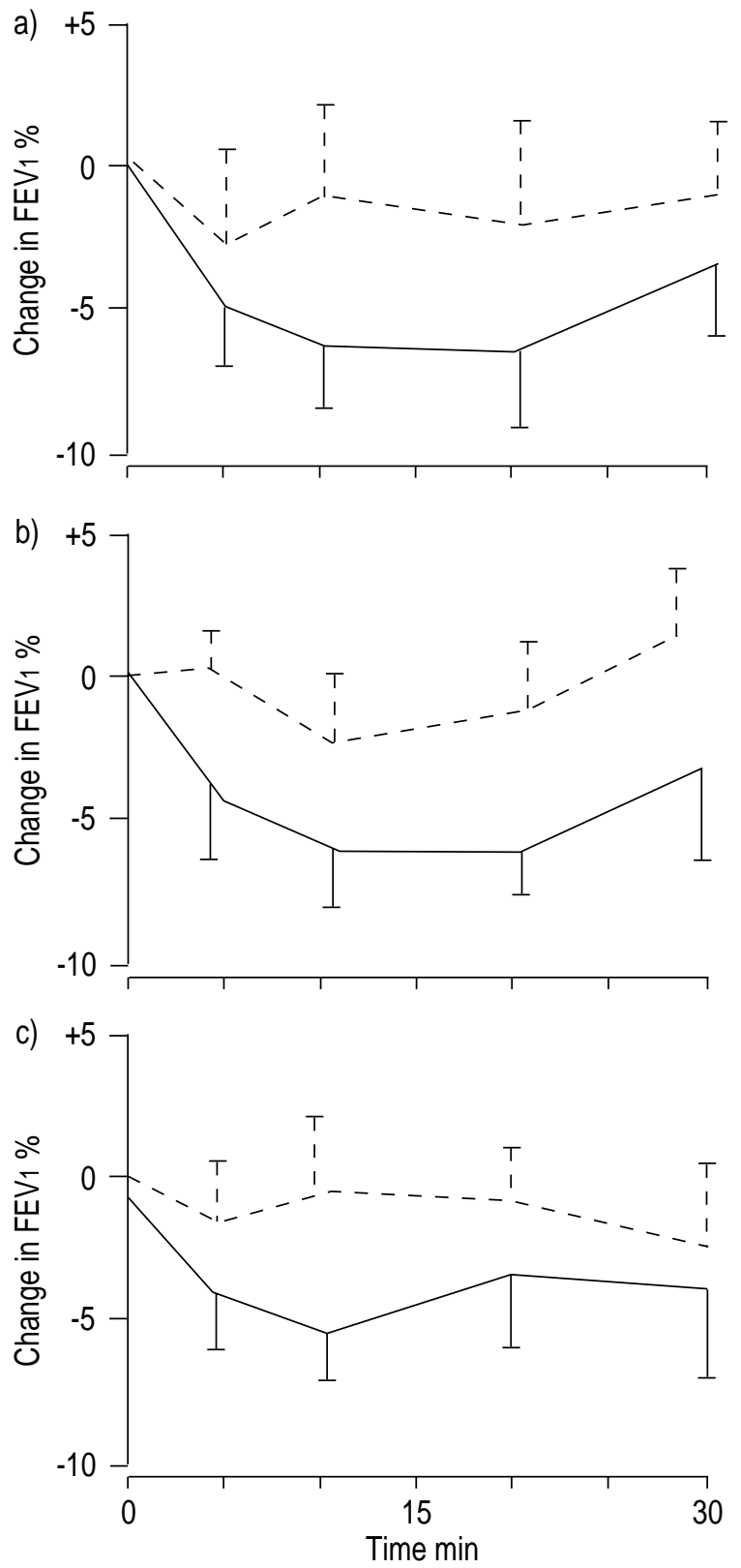

Fig. 2.- Time-course of changes in forced expiratory volume in one second (FEV1) as per cent of pre-allergen FEV 1 after vehicle (----) and the low dose allergen exposure (-) on a) day 1, b) day 3 and c) day 7 . The changes in FEV1 were very small after these doses of allergen $(n=7)$. Data are reported as mean \pm SEM.

effect on the late asthmatic response at 5-6 h postallergen was $\sim 30 \%$.

\section{Inflammation}

Effects of repeated low-dose allergen exposure on blood eosinophils and serum eosinophil cationic protein. The number of eosinophilic cells in blood before the diluent and low-dose allergen periods were similar $(0.26 \pm$ $0.05 \times 10^{9} \cdot \mathrm{L}^{-1}, \quad 0.23 \pm 0.04 \times 10^{9} \cdot \mathrm{L}^{-1}$, respectively) During the period of low-dose allergen exposure, there was a small increase in blood eosinophils versus 


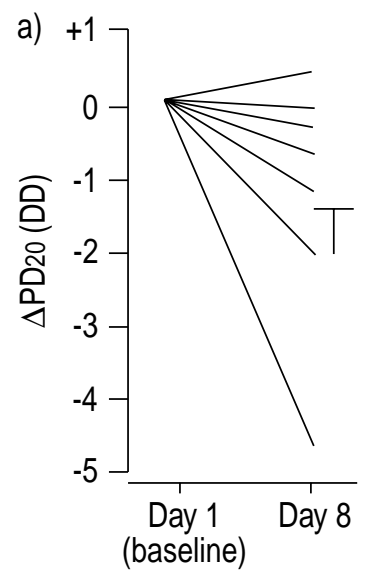

b)

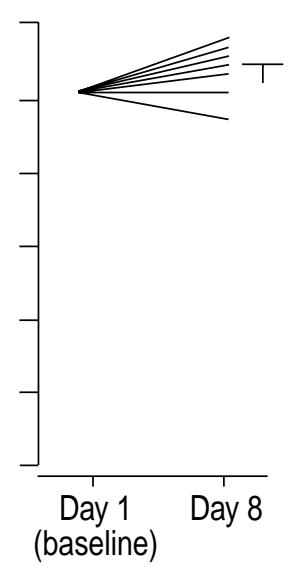

Fig. 3. - Changes $(\triangle)$ in methacholine responsiveness, measured as methacholine dose to cause a $20 \%$ fall in forced expiratory volume in one second (PD20) during a) low-dose allergen period; and b) placebo period. The changes in responsiveness are shown as doubling doses (DD). During the placebo period, there was a slight improvement in methacholine responsiveness, whereas the repeated low dose allergen exposure caused a significant increase in methacholine responsiveness.

the diluent week on day $9\left(0.08 \pm 0.04 \times 10^{9} \cdot \mathrm{L}^{-1}\right.$ and $-0.07 \pm 0.03 \times 10^{9} \cdot \mathrm{L}^{-1}$, respectively, $\mathrm{p}=0.007$; fig. 5). The baseline S-ECP values were not significantly different between the two treatments, and there were no significant changes in this parameter during the lowdose allergen exposure compared to the diluent exposure $\left(5.7 \pm 3.4 \mu \mathrm{g} \cdot \mathrm{L}^{-1}\right.$ and $1.4 \pm 4.5 \mu \mathrm{g} \cdot \mathrm{L}^{-1}$, respectively $\mathrm{p}=0.25$ ).

Effects of repeated low-dose allergen exposure on sputum eosinophils and interleukin-5. After the period of repeated low-dose allergen exposure, the number of eosinophils in sputum were significantly increased versus the diluent period (fig. $6 ; \mathrm{p}=0.04$ ). Numerically and compared with the placebo exposure period,

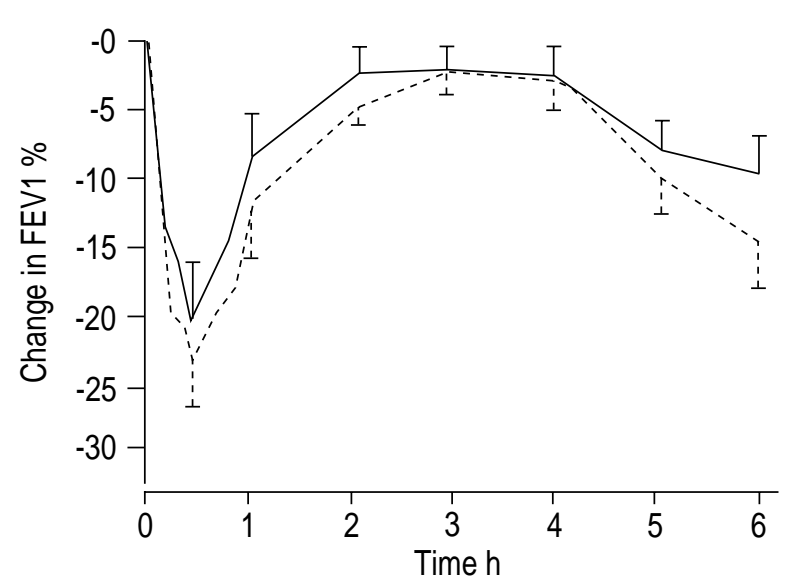

Fig. 4. - Time-course of changes in forced expiratory volume in one second $(\mathrm{FEV} 1)$ as per cent of pre-allergen FEV1 after the highdose allergen challenge on day 9, $24 \mathrm{~h}$ after the last vehicle (-----) or low-dose allergen exposure (-). The late asthmatic response, at 5 and $6 \mathrm{~h}$ post allergen, was significantly smaller in magnitude after the low-dose allergen exposure period compared to after the placebo period $(\mathrm{p}=0.032)$. Data are reported as mean \pm SEM.

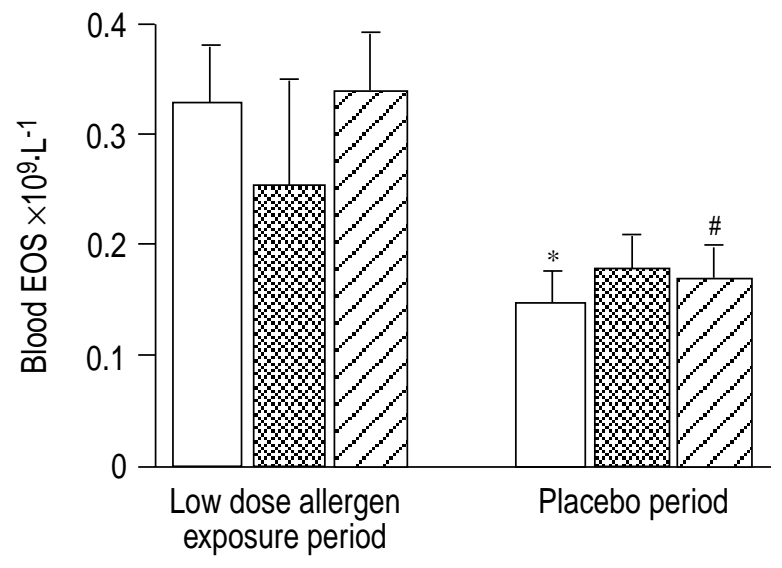

Fig. 5. - Number of circulating eosinophils (EOS) on day 9 prior to high-dose allergen challenge $(\square)$, and 3 (图) and $6 \mathrm{~h}(\mathbb{Z})$ after the challenge. Data are reported as mean \pm SEM. *: $p=0.006$, versus low dose; \#: $\mathrm{p}=0.007$ versus low dose.

allergen exposure increased mean sputum IL-5 $\left(27.7 \pm 22.0-90.2 \pm 56.4 \mathrm{pg} \cdot \mathrm{mg}^{-1}\right)$ and mean sputum eotaxin (not measurable-26.3 $\pm 17.3 \mathrm{pg} \cdot \mathrm{mg}^{-1}$ ), but there was a substantial variability in these parameters, and the changes are not statistically significant.

Effects of high-dose allergen-challenge on B-eosinophils and serum eosinophil cationic protein. B-eosinophils on day 9, before the high-dose allergen exposure was significantly higher after the low-dose allergen exposure period than after the placebo period, $0.33 \pm$ $0.03 \times 10^{9} \cdot \mathrm{L}^{-1}$ versus $0.20 \pm 0.04 \times 10^{9} \cdot \mathrm{L}^{-1}, \mathrm{p}=0.025$. At 3 and $6 \mathrm{~h}$ after the high-dose allergen challenge, there was no significant change in blood eosinophils from baseline values compared after the low-dose allergen and diluent exposure period respectively (fig. 5). S-ECP was on similar levels before the highdose allergen challenges on day 9, and there was no

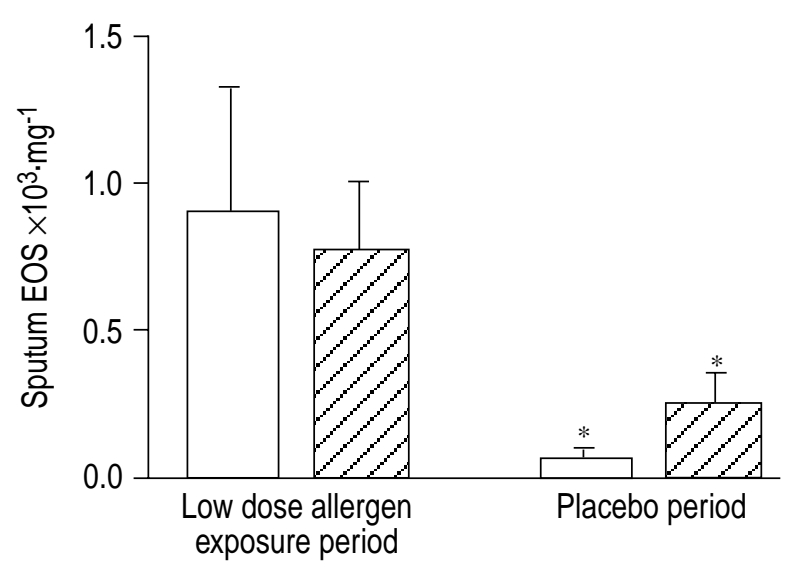

Fig. 6. - Number of eosinophils in induced sputum (as number of cells $\cdot \mathrm{mg}^{-1}$ of sputum plugs) $6 \mathrm{~h}$ after the last of seven exposures to a low-dose of allergen or placebo $(\square)$ on day 8 and $6 \mathrm{~h}$ after the high dose allergen challenge on day $9(\mathbb{Z})$. There were significantly higher numbers of eosinophils in sputum after the repeated allergen exposure period, both before and after a high-dose allergen challenge. Data are reported as mean \pm SEM. $*: p=0.04$ versus low dose. 
Table 2. - Concentrations of interleukin-5 (IL-5) and eota$x$ in in sputum (mean \pm SEM) $6 \mathrm{~h}$ after the last of seven low-dose allergen/placebo exposures, and $6 \mathrm{~h}$ after the high-dose allergen challenge $(n=4)$

\begin{tabular}{lcc}
\hline & $\begin{array}{c}\text { IL-5 } \mathrm{pg} \cdot \mathrm{mg}^{-1} \\
\text { sputum }\end{array}$ & $\begin{array}{c}\text { Eotaxin } \mathrm{pg} \cdot \mathrm{mg}^{-1} \\
\text { sputum }\end{array}$ \\
\hline $\begin{array}{l}\text { Placebo exposure } \\
\text { Placebo exposure, 6 } \mathrm{h} \\
\text { postallergen challenge }\end{array}$ & $\begin{array}{c}27.7 \pm 22.0 \\
\text { Allergen exposure }\end{array}$ & $0 \pm 0$ \\
$\begin{array}{l}\text { Allergen exposure, } 6 \mathrm{~h} \\
\text { postallergen challenge }\end{array}$ & $90.2 \pm 56.4$ & $26.3 \pm 114.8$ \\
\hline
\end{tabular}

significant change in S-ECP after 3 and $6 \mathrm{~h}$ when comparing after the low-dose allergen and the diluent exposure periods (data not shown).

Effects of high-dose allergen-challenge on sputum eosinophils and interleukin-5. Six $\mathrm{h}$ after the highdose allergen challenge after the diluent period, there was a trend towards an increase in the number of eosinophils in sputum, which however, was not observed after the repeated low-dose allergen exposure period (fig. 6; $p=$ nonsignificant). The IL-5 levels in sputum tended to increase after the high-dose allergen challenge after the placebo period $\left(27.7 \pm 22.0-139.1 \pm 114.8 \mathrm{pg} \cdot \mathrm{mg}^{-1} ; \mathrm{p}=\right.$ nonsignificant), but did not further increase versus the levels seen after the low-dose allergen exposure period $\left(90.2 \pm 56.4\right.$ to $97.9 \pm 42.9 \mathrm{pg} \cdot \mathrm{mg}^{-1} ; \mathrm{p}=$ nonsignificant $)$. Furthermore, no overt changes in sputum eotaxin were observed during the repeated low-dose allergen exposure period (table 2).

Effects of repeated low-dose allergen exposure and high dose-allergen challenge on peripheral blood lymphocyte fluorescence-activated cell sorter analysis. Similar levels of CD4- and CD8-cells were found in peripheral blood after the vehicle and the repeated low-dose allergen exposure weeks (table 3). After the high-dose allergen challenge, a small increase in mainly CD4-cells, but also in CD-8 cells, was found (table 3 ) after the low-dose allergen exposure period.

Effects of repeated low-dose allergen exposure on T-lymphocyte cell culture. Magnetically enriched peripheral blood CD4-cells, taken $6 \mathrm{~h}$ after the high-dose allergen challenge (on day 9), responded with proliferation in response to Concanavaline A (Sigma Chemical Co., St Louis, MO, USA) in vitro (table 3). The proliferative response was attenuated in CD4-cells acquired after the repeated low-dose allergen exposure period (table 3 ).

CD34 cells. Magnetically purified bone marrow CD34cells responded with colony formation when stimulated with IL-5, GM-CSF and SCF, as well as autologous serum taken during a late asthmatic reaction induced by the screening allergen challenge. This colony formation was significantly attenuated in cells acquired from the patients after the repeated low-dose allergen exposure period (table 3 ). No significant difference in the relative amount of eosinophils was seen between the different samples and culture conditions (data not shown).

\section{Discussion}

This study has shown that repeated individualized low doses of allergen slightly reduce the late asthmatic response, despite documented parallel increased bronchial methacholine responsiveness in the same patients. Furthermore, the late allergen response was attenuated despite a higher number of eosinophils in the airways prior to the high-dose allergen challenge, as well as during the late response.

Several investigators have previously documented increased bronchial hyperresponsiveness after repeated low-dose allergen exposures [20-24]. In addition to increased bronchial hyperresponsiveness, it has previously been shown that this type of exposure increases the variability in lung function and increases asthma symptoms [22]. It has also been shown that the number of sputum eosinophils and the levels of sputum IL-5 are increased [23], which is further confirmed in this study. Thus, the repeated allergen exposure protocol induces, by definition, a mild exacerbation of asthma, since most disease variables are worsened. The only component of asthma not adversely affected with these protocols, is the baseline lung function, measured as FEV1.

In an experimental room with cat allergen present in dust, levels of allergen in air can reach $\sim 5 \mathrm{ng} \cdot \mathrm{m}^{-3}$ when the room is vacuum cleaned [33]. Since the tidal volume of breathing is $\sim 8 \mathrm{~L} \cdot \mathrm{min}^{-1}$, the total volume of air being ventilated during $24 \mathrm{~h}$ is $\sim 10 \mathrm{~m}^{3}$. The mean dose of allergen given to the patients during the low-dose exposure period was approximately $50 \mathrm{ng} \cdot \mathrm{day}^{-1}$, and is, therefore, of a similar magnitude as a $24 \mathrm{~h}$ exposure in a room with cat allergen under the reported conditions. The model presented in this paper is, therefore, experimental and does not exactly copy the natural

Table 3. - Changes in blood CD4 and CD8 numbers and proliferation, and bone marrow CD34 growth, after allergen or placebo exposure

\begin{tabular}{|c|c|c|c|c|c|}
\hline Exposure & $\begin{array}{l}\text { CD4 }+ \text { cells } \\
\quad \times 10^{9} \cdot \mathrm{L}^{-1}\end{array}$ & $\begin{array}{l}\text { CD8 }+ \text { cells } \\
\quad \times 10^{9} \cdot \mathrm{L}^{-1}\end{array}$ & $\begin{array}{l}\text { CD4 Thymidine } \\
\text { incorporation } \\
\text { after ConA }{ }^{\#} \mathrm{cpm}\end{array}$ & $\begin{array}{l}\text { CD8 Thymidine } \\
\text { incorporation } \\
\text { after ConA }{ }^{\#} \mathrm{cpm}\end{array}$ & CD34-cells cfus \\
\hline Placebo exposure & $0.82 \pm 0.12$ & $0.39 \pm 0.06$ & $26000 \pm 4100$ & $52700 \pm 10100$ & $365 \pm 124$ \\
\hline Allergen exposure & $0.82 \pm 0.05$ & $0.51 \pm 0.11$ & $10900 \pm 2900 *$ & $12400 \pm 3500$ & $74 \pm 43 *$ \\
\hline
\end{tabular}

Data are reported as mean \pm SEM. ConA: concanavallin A; Cpm: counts per minute; cfu: colony forming units; ${ }^{\#}$ : collected $6 \mathrm{~L}$ after the terminating high-dose allergen challenges; ${ }^{*}: \mathrm{p}<0.05$. 
situation. However, the degree of inflammation and induced bronchial methacholine hyperresponsiveness is similar to, or slightly weaker than, that induced by natural allergen exposure [12-14].

The attenuated late allergen response after the low-dose allergen exposure period was not pronounced, but in sharp contrast to the induced increased methacholine responsiveness in the same patients. This attenuated late asthmatic response is of a similar degree to that seen during immunotherapy with pollen, given subcutaneously, where the clinical improvement is accompanied by an attenuation of the late asthmatic response [34, 35]. However, in contrast to injection immunotherapy [36], the present study patients developed increased methacholine hyperresponsiveness, indicating worsening of asthma, which should be considered when inhalation immunotherapy is tested experimentally. Perhaps recombinant antigens given by inhalation, instead of crude allergen extract, will be more beneficial with regard to nonspecific bronchial hyperresponsiveness [37].

Previous studies have shown that the presence of eosinophilic inflammation is of importance for the allergen responsiveness and the degree of the late response [38]. By contrast, despite more pronounced eosinophilic inflammation in the airways after the lowdose allergen exposure period, the late asthmatic response was attenuated in the present study. Thus, the degree of pre-existing eosinophilia does not seem to be a crucial determinant for the degree of the late response in this model. Neither were any overt changes in sputum concentrations of IL-5 or eotaxin found, arguing against substantial changes in these cytokines locally as a mechanism of attenuation of the late asthmatic response after low-dose allergen exposure.

To avoid carry-over effects of one study period to another, the authors chose, as in a previous study [22], to give all patients a single dose of oral prednisolone $(30 \mathrm{mg})$ after the high-dose allergen challenges, both at screening and after the allergen/placebo exposure periods. Thus, all study periods were preceded by a single dose of oral prednisolone, but with at least a 10 day wash-out period. Therefore, the prednisolone treatment should not have influenced the differences in outcomes of this study.

The attenuated LAR was associated with a parallel reduction of responsiveness of several inflammatory cells, collected systemically, including CD4- and CD8cells, as well as bone marrow CD34-cells. These data support the notion that allergen-induced airway responses also involve systemic processes, including peripheral T-cells and bone marrow, and these may be involved in the regulation of reduced responses induced by low-dose allergen exposure.

In summary, this study shows that repeated exposure to a low dose of allergen reduces the degree of a late asthmatic response, despite increased methacholine bronchial hyperresponsiveness. Thus, low doses of allergen can theoretically reduce symptoms induced by high-dose allergen challenge. Further studies with prolonged time of low-dose allergen exposure, or studies of allergen avoidance, must be performed to document how important these effects are in the clinical situation.
Acknowledgements. The authors are grateful to K. Pettersson, E. Ågren and C. Malmhäll for technical assistance, and to O. Löwhagen and B-E. Skoogh for helpful discussions in the planning and discussions of this study. The fluorescenceactivated cell sorter analysis was performed under the supervision of B. Andersson, at the Dept of Clinical Immunology, Sahlgrenska University Hospital.

\section{References}

1. Munir AK, Einarsson R, Schou C, Dreborg SK. Allergens in school dust. I. The amount of the major cat (Fel d 1) and dog (Can f 1) allergens in dust from Swedish schools is high enough to probably cause perennial symptoms in most children with asthma who are sensitized to cat and dog. J Allergy Clin Immunol 1993; 91: 1067-1074.

2. Munir AK, Einarsson R, Dreborg SK. Mite (Der p 1, Der f 1), cat (Fel d 1) and dog (Can f 1) allergens in dust from Swedish day-care centers. Clin Exp Allergy 1995; 25: 119-126.

3. Raunio P, Pasanen AL, Reiman M, Virtanen T. Cat, $\mathrm{dog}$, and house-dust-mite allergen levels of house dust in Finnish apartments. Allergy 1998; 53: 195-199.

4. Custovic A, Fletcher A, Pickering CA, et al. Domestic allergens in public places III: house dust mite, cat, dog and cockroach allergens in British hospitals. Clin Exp Allergy 1998; 28: 53-59.

5. Custovic A, Simpson A, Pahdi H, Green RM, Chapman MD, Woodcock A. Distribution, aerodynamic characteristics, and removal of the major cat allergen Fel d 1 in British homes. Thorax 1998; 53: 33-38.

6. Enberg RN, Shamie SM, McCullough J, Ownby DR. Ubiquitous presence of cat allergen in cat-free buildings: probable dispersal from human clothing. Ann Allergy 1993; 70: 471-474.

7. Munir AK, Einarsson R, Kjellman NI, Bjorksten B. Mite (Der pI, Der fI), and cat (Fel d 1) allergens in the homes of babies with a family history of allergy. Allergy 1993; 48: 158-163.

8. Platts-Mills TA, Tovey ER, Mitchell EB, Moszoro H, Nock P, Wilkins SR. Reduction of bronchial hyperreactivity during prolonged allergen avoidance. Lancet 1982; 2: 675-678.

9. Ehnert B, Lau-Schadendorf S, Weber A, Buettner P, Schou C, Wahn U. Reducing domestic exposure to dust mite allergen reduces bronchial hyperreactivity in sensitive children with asthma. J Allergy Clin Immunol 1992; 90: 135-138.

10. Peroni DG, Boner AL, Vallone G, Antolini I, Warner JO. Effective allergen avoidance at high altitude reduces allergen-induced bronchial hyperresponsiveness. Am J Respir Crit Care Med 1994; 149: 14421446.

11. Cockcroft DW, Ruffin RE, Hargreave FE. Appearance of allergen-induced increases in airway responsiveness only after repeated allergen inhalations in two subjects. Clin Exp Allergy 1989; 19: 225-227.

12. Boulet LP, Cartier A, Thomson NC, Roberts RS, Dolovich J, Hargreave FE. Asthma and increases in nonallergic bronchial responsiveness from seasonal pollen exposure. J Allergy Clin Immunol 1983; 71: 399-406. 
13. Sotomayor H, Badier $\mathrm{M}$, Vervloet $\mathrm{D}$, Orehek J. Seasonal increase of carbachol airway responsiveness in patients allergic to grass pollen. Reversal by corticosteroids. Am Rev Respir Dis 1984; 130: 56-58.

14. Boulet LP, Turcotte H, Boutet M, Montminy L, Laviolette M. Influence of natural antigenic exposure on expiratory flows, methacholine responsiveness, and airway inflammation in mild allergic asthma. $J$ Allergy Clin Immunol 1993; 91: 883-893.

15. Herxheimer $\mathrm{H}$. The late bronchial reaction in induced asthma. Int Arch Allergy App Phys 1952; 3: 323-328.

16. Booij-Noord H, de Vries K, Sluiter HJ, Orie NG. Late bronchial obstructive reaction to experimental inhalation of house dust extract. Clin Allergy 1972; 2: 43-61.

17. Cockcroft DW, Ruffin RE, Dolovich J, Hargreave FE. Allergen-induced increase in non-allergic bronchial reactivity. Clin Allergy 1977; 7: 503-513.

18. Sporik R, Chapman MD, Platts-Mills TAE. House dust mite exposure as a cause of asthma. Clin Exp Allergy 1992; 22: 897-906.

19. Sicherer SH, Wood R, Eggleston PA. Determinants of airway responses to cat allergen: Comparison of environmental challenge to quantitative nasal and bronchial allergen challenge. J Allergy Clin Immunol 1997; 99: 798-805.

20. Ihre E, Zetterstrom O. Increase in bronchial responsiveness after repeated inhalation of low doses of allergen. Clin Exp Allergy 1993; 23: 298-305.

21. Roquet A, Lagging E, Ihre E, et al. No signs of activity markers in peripheral blood despite increased bronchial reactivity after repeated low-dose allergen exposure. APMIS 1998; 106: 293-299.

22. Palmqvist M, Pettersson K, Sjöstrand M, Andersson $\mathrm{B}$, Löwhagen $\mathrm{O}$, Lötvall J. Mild exacerbation of asthma induced by individualised low-dose repeated allergen exposure. A double-blind evaluation. Respir Med 1998; 92: 1223-1230.

23. Sulakvelidze I, Inman MD, Rerecich T, O'Byrne PM. Increases in airway eosinophils and interleukin-5 with minimal bronchoconstriction during repeated lowdose allergen challenge in atopic asthmatics. Eur Respir J 1998; 11: 821-827.

24. Arshad SH, Hamilton RG, Adkinson NF Jr. Repeated aerosol exposure to small doses of allergen. A model for chronic allergic asthma. Am J Respir Crit Care Med 1998; 157: 1900-1906.

25. Herxheimer H. Bronchial hypersensitization and hyposensitization in man. Int Arch Allergy 1951; 2: 40-59.

26. Rosenthal RR, Norman PS, Summer WR. Bronchoprovocation: effect on priming and desensitization phenomenon in the lung. J Allergy Clin Immunol 1975; 56: $338-346$.
27. Cui ZH, Pullerits T, Lindén A, Skoogh BE, Lötvall J. Repeated low dose allergen challenge increases acetylcholine responsiveness but attenuates high dose allergen response in guinea pigs. Eur Respir J 1997; 10: Suppl. 25, 4765.

28. Pizzichini E, Pizzichini MM, Efthimiadis A, et al. Indices of airway inflammation in induced sputum: reproducibility and validity of cell and fluid-phase measurements. Am J Respir Crit Care Med 1996; 154: 308-317.

29. Girgis-Gabardo A, Kanai N, Denburg JA, Hargreave FE, Jordana M, Dolovich J. Immunocytochemical detection of granulocyte-macrophage colonystimulating factor and eosinophil cationic protein in sputum cells. J Allergy Clin Immunol 1994; 93: 945947.

30. Inman MD, Watson R, Cockcroft DW, Wong BJ, Hargreave FE, O'Byrne PM. Reproducibility of allergen-induced early and late asthmatic responses. J Allergy Clin Immunol 1995; 95: 1191-1195.

31. Gauvreau GM, Watson RM, Rerecich TJ, Baswick E, Inman MD, OByrne PM. Repeatibility of allergeninduced airway inflammation. J Allergy Clin Immunol 1999; 104: 66-71.

32. Popov TA, Pizzichini MM, Pizzichini E, et al. Some technical factors influencing the induction of sputum for cell analysis. Eur Respir J 1995; 8: 559-565.

33. de Blay F, Spirlet F, Gries P, Casel S, Ott M, Pauli G. Effects of various vacuum cleaners on the airborne content of major cat allergen (Fel d 1). Allergy 1998; 53: 411-414.

34. Van Bever HP, Stevens WJ. Suppression of the late asthmatic reaction by hyposensitization in asthmatic children, allergic to house dust mite (Dermatophagoides pteronyssinus). Clin Exp Allergy 1989; 19: 399404.

35. Van Bever HP, Stevens WJ. Evolution of the late asthmatic reaction during immunotherapy and after stopping immunotherapy. J Allergy Clin Immunol 1990; 86: 141-146.

36. Sundin B, Lilja G, Graff-Lonnevig V, et al. Immunotherapy with partially purified and standardized animal dander extracts. I. Clinical results from a double-blind study on patients with animal dander asthma. J Allergy Clin Immunol 1986; 77: 478-487.

37. Valenta R, Vrtala S. Recombinant allergens for specific immunotherapy. Allergy 1999; 54: Suppl. 56, 43-44.

38. Durham SR, Kay AB. Eosinophils, bronchial hyperreactivity and late-phase asthmatic reactions. Clin Allergy 1985; 15: 411-418. 